\title{
Properties and modification mechanisms of nano-zirconia filled reactive powder concrete
}

\author{
Baoguo Han ${ }^{1, *}$, Zhu Wang ${ }^{1}$, Shuzhu Zeng ${ }^{1}$, Daocheng Zhou ${ }^{1}$, Xun $\mathrm{Yu}^{2,3}$, Xia Cui ${ }^{1}$, Jinping Ou ${ }^{1}$ \\ ${ }^{1}$ School of Civil Engineering, Dalian University of Technology, Dalian 116024, China \\ ${ }^{2}$ Department of Mechanical Engineering, New York Institute of Technology, New York, NY 11568 , \\ USA \\ ${ }^{3}$ School of Mechanical Engineering, Wuhan University of Science and Technology, Wuhan, 430081, \\ China \\ *Corresponding author: hithanbaoguo@163.com, hanbaoguo@dlut.edu.cn
}

\begin{abstract}
The mechanical and electrical properties of reactive powder concrete (RPC) with nano- $\mathrm{ZrO}_{2}(\mathrm{NZ})$ are investigated in this research. The reinforcing mechanisms of $\mathrm{NZ}$ to RPC are studied through thermogravimetry (TG) analysis, scanning electron microscope (SEM) observation and X-Ray powder diffraction (XRD) analysis. Research results indicate that the NZ has obvious modifying effect to RPC. The flexural, compressive and splitting strengths of RPC with NZ at curing age of 28 days achieve increases of 36.6\%/4.19 MPa, 16.3\%/16.18 MPa and 34.0\%/1.08 MPa, respectively, compared to plain RPC. The addition of NZ makes a $20 \%$ decrease in the electrical conductivity of RPC. The NZ does not accelerate the hydration process of RPC. However, the microstructures of NZ filled RPC are denser than that of plain RPC. This leads to the reduction of the growth space of calcium hydroxide $(\mathrm{CH})$ crystals, thus the size of $\mathrm{CH}$ crystals is reduced. Furthermore, NZ can reduce $\mathrm{CH}$ crystal orientation to improve the microstructures of the composites.
\end{abstract}

Keywords: reactive powder concrete; nano- $\mathrm{ZrO}_{2}$; strength, electrical conductivity; reinforcing mechanisms. 


\section{Introduction}

With the rapid development of building industry, high-performance concrete materials are in an urgent demand. Properties of concrete have been undergoing changes through technological advancement [1]. Reactive powder concrete (RPC) is known as a type of ultra-high-performance concrete. The primary improvements of RPC include the homogeneity of particle size, porosity and microstructure of matrix $[2,3]$. Compared to the microstructure of conventional concrete or even highperformance concrete, RPC has a denser microstructure [4, 5]. Its compressive strength of RPC can reach up to $800 \mathrm{MPa}$ [6]. However, high-strength concrete is associated with low fracture toughness, low tensile strain and low impact resistance, which limit their applications.

Nano fillers with small size effect and boundary effect can not only fill the pores inside concrete [7], but also improve the interface structure of concrete and aggregate to increase the strength, toughness, impermeability and durability of concrete $[8,9]$. As a kind of inorganic non-metal oxide, nano- $\mathrm{ZrO}_{2}(\mathrm{NZ})$ features good wearability and anti-corrosion performance. NZ with high strength, high toughness and good dispersion is an excellent toughening material for ceramics. Because of small size effect and phase transition effect of NZ, the density of ceramics can be increiased and the diffusion of micro-cracks of ceramics can be blocked. Therefore, the mechanical strength of ceramics can be significantly enhanced and fracture toughness of ceramics can be increased [10]. Inspired by the research of NZ in the field of ceramics, NZ was used in the field of cement and concrete materials. Soleymani found that the flexural 
strength of NZ filled ordinary Portland cement paste increased 25\%/1.1 MPa at curing age of 28 d [11]. Nazari et al.(Nazari et al. 2010a) observed that the flexural and splitting strengths of NZ filled ordinary Portland cement paste at curing age of $28 \mathrm{~d}$ are higher than those of the plain cement paste. The optimal amount of NZ is $1 \%$, which leads to increases in flexural and splitting strength of 31.8\%/1.4 MPa and 83.3\%/1.5 MPa, respectively [12]. They also studied the compressive strength and workability of NZ filled ordinary Portland cement paste [13, 14]. The compressive strength at curing age of $28 \mathrm{~d}$ increases first and then decreases with the increase of $\mathrm{NZ}$ content. The maximum increase in compressive strength is $18.5 \% / 6.8 \mathrm{MPa}$. In addition, Soleymani studied the effect of NZ on the pore structure property of cement paste. Experimental results showed that the addition of $\mathrm{NZ}$ improves the pore structure of cement paste, and the refined extent of pore structure increases with decreasing NZ content [11].

Based on the above analysis, NZ is a type of promising fillers for developing high-performance cement and concrete materials. However, previous studies mainly focus on the influence of NZ on ordinary Portland cement paste. The research on the effect of NZ on RPC containing aggregate and with high strength characteristics has not been done. Furthermore, previous researchers suggested that reinforcing mechanisms of NZ to ordinary Portland cement paste include filling pores and improving the pore structures $[13,14]$, which are insufficient to fully understanding the effect of NZ to cement and concrete materials. Therefore, RPC with NZ at levels of $0.0 \%, 0.5 \%, 1.0 \%, 3.0 \%$ and $5.0 \%$ were fabricated in this study. Their flexural, 
compressive, splitting and electrical properties at curing age of $3 \mathrm{~d}$ and $28 \mathrm{~d}$ are investigated. Thermogravimetry (TG), scanning electron microscope (SEM) and XRay powder diffraction (XRD) are used to analyze the reinforcing mechanisms of NZ to RPC.

\section{Experiment}

\subsection{Materials}

The NZ with an average particle size of $20 \mathrm{~nm}$ provided by Nanjing Haitai Nanomaterials Co. Ltd. in China is used as the filler. Its SEM image is shown in Fig. 1. The Portland cement (P.O 42.5R) provided by Dalian Onoda Cement Co. Ltd. in China was used as the binder. Silica fume is a commercially available product by Elkem Materials Ltd. The fly ash provided by Dalian Daokete Building Materials Co. Ltd. in China was used as the mineral admixture. Quartz sand with a size range of 0.12-0.83 mm was used as aggregate. RHEOPLUS 411 (BASF) superplasticizer was used to adjust the workability of the concrete mixture and to assist NZ dispersion. Stainless steel gauzes with opening of $40 \mathrm{~mm} \times 60 \mathrm{~mm}$ were used to make electrodes.

\subsection{Preparation}

The content levels of NZ are $0.5 \%, 1.0 \%, 3.0 \%, 5.0 \%$ by weight of cement, respectively. The water to binder ratio was fixed at 0.24 for all the mixtures. The detail mix proportions are shown in Table 1 . In order to mix NZ uniformly and keep good workability of the mixture, water reducer was first put into the water containing 
NZ. The progress of fabricating NZ filled RPC is presented in Fig. 2. The details are as following: (1) Water, water reducer, NZ, cement, silica fume, fly ash and sand were weighted as mix proportions. (2) Water, NZ and water reducer were mixed by a Constant Speed Stirrer (DW-2 DC, provided by Chinese Yu Hua Instrument Ltd.) at low speed (relation and revolution of mixing blade is $140 \pm 5 \mathrm{r} / \mathrm{min}$ and $62 \pm 5 \mathrm{r} / \mathrm{min}$ ) for 10 s. (3) The silica fume was put into the suspension slowly and mixed at low speed for $60 \mathrm{~s}$. (4) The cement and fly ash were put into the mixing pot and mixed at low speed firstly for $120 \mathrm{~s}$ and then at fast speed (relation and revolution of mixing blade is $258 \pm 10 \mathrm{r} / \mathrm{min}$ and $125 \pm 10 \mathrm{r} / \mathrm{min}$ ) for $120 \mathrm{~s}$. (5) The sand was put into the suspension and mixed at low speed firstly for $60 \mathrm{~s}$ and at fast speed for $240 \mathrm{~s}$. (6) The mixture was poured into the oiled mould (40 $\mathrm{mm} \times 40 \mathrm{~mm} \times 40 \mathrm{~mm}$ and $40 \mathrm{~mm} \times 40$ $\mathrm{mm} \times 160 \mathrm{~mm}$ ) and the mould was put on the electric vibrator to eliminate bubbles. (7) Two electrodes were embedded in the mixture whose size is $40 \mathrm{~mm} \times 40 \mathrm{~mm} \times 160 \mathrm{~mm}$ (as shown in Fig. 3(a))[15]. (8) The composites were cured at temperature of $20.0^{\circ} \mathrm{C}$ in $95 \%$ relative humidity for $24 \mathrm{~h}$ before demold. Then half of specimens were cured for $2 \mathrm{~d}$ and others were cured for $27 \mathrm{~d}$ in water at $20 \pm 1^{\circ} \mathrm{C}$.

The preparation process of plain RPC is same as that of NZ filled RPC except he steps (1) and (2), in which NZ was not added.

The samples for TG and XRD test were cement paste (its mix proportions as shown in Table 2) because the addition of sand may affect the test accuracy. One reason is that the weight of dry sand does not decrease with increasing temperatures and that the amount of sand in samples for TG is random. The other reason is that the 
XRD characteristic peaks of sand are too strong to make the XRD peaks of hydration products of cement observable. The manufacture process of cement paste was the same with the cement mortar except the process of adding sand. After hydration for $3 \mathrm{~d}$ and $28 \mathrm{~d}$, the cement pastes was crushed, milled and sieved at $80 \mu \mathrm{m}$ for TG and XRD test. In addition, samples were dried at $50^{\circ} \mathrm{C}$ for $24 \mathrm{~h}$ to avoid the effect of absorbed water.

The samples for SEM selected from the composites after testing flexural and compressive strength at age of $28 \mathrm{~d}$.

\subsection{Measurement}

The tested properties of the specimens include flexural strength, compressive strength, splitting strength, and electrical resistivity. The flexural strength was measured by a mortar folding meter DKZ-5000 at age of $3 \mathrm{~d}$ and $28 \mathrm{~d}$. All the specimens were loaded to failure at constant loading rate of $0.5 \mathrm{~mm} / \mathrm{min}$. The average value of flexural strengths of 3 specimens in each group was recorded as the final flexural strength if the maximum or the minimum value was $10 \%$ less than the average value. The compressive strength was also measured according to GB/T17671-1999 of China (Method of testing cements-determination of strengthISO). The specimens of $40 \mathrm{~mm} \times 40 \mathrm{~mm} \times 160 \mathrm{~mm}$ were broken in two near the middle after flexural test. The two pieces were measured by a compression testing machine YAW-2000D provided by China Jinan Era Assay Testing Machine Co. Ltd. with a contact area of $40 \mathrm{~mm} \times 40 \mathrm{~mm}$. All the specimens were loaded to failure at 
constant loading rate of $1.2 \mathrm{~mm} / \mathrm{min}$. The average value of compressive strengths of 6 types of specimens in each group was recorded as the final compressive strength if the maximum or the minimum value was $10 \%$ less than the average value. Splitting strength was also measured by the universal material testing machine WDW-200E. The specimens were put on the center of platen and the steel bearing plate and the wooden cushion were put between the upper platen and the lower platen (as shown in Fig. 4). The alternating current (AC) electrical resistivity of specimens was measured by a two-probe method using a digital logger (U1733C, Agilent Technologies, Inc., USA).

Field Emission Scanning Electron Microscope (Nova Nano SEM 450, American FEI Ltd.) was used to observe the microstructures of the composites. Environmental Scanning Electron Microscope (Quanta450, American FEI Ltd.) was used to observe the distribution of NZ in RPC. TG analysis was performed using a METTLER TOLEDO STARe system to get the amount of $\mathrm{CH}$ and other hydration products. The condition of TG analysis was under nitrogen atmosphere at a heating rate of $10{ }^{\circ} \mathrm{C} / \mathrm{min}$ up to $1000^{\circ} \mathrm{C}$. XRD (Bruker D8 Advance, Bruker German) was applied for testing the change in tendency of calcium hydroxide $(\mathrm{CH})$ crystals inside the composites caused by NZ.

\section{Result and Discussion}

\subsection{Flexural strength}


Fig. 5 shows flexural strength of NZ filled RPC at curing age of $3 \mathrm{~d}$ and $28 \mathrm{~d}$. As shown in Fig. 5, the flexural strength of NZ filled RPC increases first and then decreases with increasing NZ content at curing age of $3 \mathrm{~d}$ and $28 \mathrm{~d}$. The blue line in Fig. 5 shows sum of the flexural strength of NZ filled RPC at curing age of $3 \mathrm{~d}$ and 3.75 $\mathrm{MPa}$ (the difference of flexural strength of plain specimens at curing age of $3 \mathrm{~d}$ and $28 \mathrm{~d})$. The difference $(3.75 \mathrm{MPa})$ is regarded as the growth of flexural strength of plain RPC with curing age. Thus, the difference of red line and blue line means the flexural strength growth attributed to the addition of NZ. It can be seen from Fig. 5 that there is no contribution of NZ to flexural strength when the content of NZ is less than $0.5 \%$. The NZ contribution to flexural strength increases with the increase of NZ content, and the optimal level of NZ content is $3.0 \%$.

Tables 3 and 4 show the relative and absolute increases in flexural strengths of RPC with different contents of NZ at curing age of $3 \mathrm{~d}$ and $28 \mathrm{~d}$, respectively. When the content of $\mathrm{NZ}$ is $0.5 \%$, the flexural strengths of the composites reach their maxima and increase by $32.0 \%$ at the curing age of $3 \mathrm{~d}$. The maximum increase at the age of $28 \mathrm{~d}$ reaches to $36.6 \% / 4.19 \mathrm{MPa}$ when the $\mathrm{NZ}$ content increases up to 3.0\%. Previous research in Ref. 11 indicated that the optimal level of NZ content is $1.0 \%$ with an improvement of 25.0\%/1.1 MPa in flexural strength of NZ filled ordinary Portland cement at the curing age of $28 \mathrm{~d}$. Maximum increase rate of NZ filled RPC is obviously higher than that of NZ filled ordinary Portland cement. This may be because that NZ has different influences on different matrices. In addition, the content and particle size of $\mathrm{NZ}$ also have influence on the flexural strength. 
Table 5 shows the relative standard deviation of flexural strengths of RPC with different NZ contents at curing age of $3 \mathrm{~d}$ and $28 \mathrm{~d}$. It can be seen from Table 5 that the discreteness of flexural strength of the composites at curing age of $3 \mathrm{~d}$ and $28 \mathrm{~d}$ ranges from 0.007 to 0.095 and 0.019 to 0.076 , respectively. It indicates that the dispersion of NZ in RPC is relatively homogeneous and flexural strength of the composites in each group is relatively stable.

\subsection{Compressive strength}

Fig. 6 shows compressive strength of NZ filled RPC at curing age of $3 \mathrm{~d}$ and 28 d. As shown in Fig. 6, the compressive strength of NZ filled RPC at the curing age of $3 \mathrm{~d}$ declines after the first growing trend and then increases as NZ content increases. However, the compressive strength of NZ filled RPC increases first and then decreases with the increase of $\mathrm{NZ}$ content at the curing age of $28 \mathrm{~d}$. And the optimal amount of NZ added into RPC is $0.5 \%$. The meaning of the blue line in Fig.6 is with the same as the above-mentioned. It can be observed that the contribution of NZ to the compressive strength of the composites is more obvious compared with that to the flexural strength, and the contribution reached its maximum when the NZ content is $3.0 \%$.

Tables 6 and 7 show the relative and absolute increases in compressive strength of RPC with different NZ contents at curing age of $3 \mathrm{~d}$ and $28 \mathrm{~d}$, respectively. It can be found that the presence of NZ has no obvious effect on the compressive strength of the composites at the curing age of $3 \mathrm{~d}$, but it has obvious impact on that at the curing 
age of $28 \mathrm{~d}$. When the content of NZ is $5.0 \%$ and $0.5 \%$, the compressive strengths at the curing age at $3 \mathrm{~d}$ and $28 \mathrm{~d}$ reach their maximum and increase by $6.1 \% / 4.05 \mathrm{MPa}$ and $16.3 \% / 16.18 \mathrm{MPa}$, respectively. Ref. 13 has reported that the maximum relative increase rate in compressive strength of NZ filled ordinary Portland cement at curing age of $28 \mathrm{~d}$ is $18.5 \%$, but the absolute increase rate in the compressive strength is only 6.8 MPa. Although the maximum increase rate in compressive strength of NZ filled RPC at curing age of $28 \mathrm{~d}$ is lower than $18.5 \%$, the maximum absolute increase in compressive strength can reach to $16.18 \mathrm{MPa}$, which is much higher than $6.8 \mathrm{MPa}$. Therefore, NZ may have strong enhancing effect to cement-based composites containing aggregate and with high strength feature.

Table $\mathbf{8}$ shows the relative standard deviation of compressive strengths of RPC with different NZ contents at curing age of $3 \mathrm{~d}$ and $28 \mathrm{~d}$. It can be seen that the discreteness of compressive strength of NZ filled RPC at curing age of $3 \mathrm{~d}$ and $28 \mathrm{~d}$ are in the range from 0.030 to 0.086 and 0.028 to 0.074 , respectively. It indicates that the dispersion of NZ in RPC is relatively homogeneous and compressive strength of the composites in each group is relatively stable.

\subsection{Splitting strength}

Fig. 7 shows splitting strength of NZ filled RPC at curing age of $3 \mathrm{~d}$ and $28 \mathrm{~d}$. As shown in Fig. 7, the splitting strength of NZ filled RPC decreases with the increasing $\mathrm{NZ}$ content at the curing age of $3 \mathrm{~d}$. However, the splitting strength of NZ filled RPC decreases first, and then increases, and finally decreases with the increase of NZ 
content at the curing age of 28 d. The meaning of the blue line in Fig. 7 is also the same as the above-mentioned. The NZ contributions to splitting strength of the composites are unobvious when the NZ content is $0.5 \%$ or $1.0 \%$, but they are obvious as the $\mathrm{NZ}$ content is $3.0 \%$ or $5.0 \%$. The optimal amount of $\mathrm{NZ}$ is also $3.0 \%$ for the splitting strength at the curing age of $28 \mathrm{~d}$.

Tables 9 and 10 give the relative and absolute increases in splitting strength of RPC with different NZ contents at curing age of $3 \mathrm{~d}$ and $28 \mathrm{~d}$, respectively. It can be observed from Tables 9 and $\mathbf{1 0}$ that when the NZ content is $3.0 \%$, the splitting strength reaches the maximum and increases 34.0\%/1.08 $\mathrm{MPa}$ at the curing age of 28 d. The results in Ref. 12 have stated that the maximum increase of splitting strength of NZ filled ordinary Portland cement paste at the curing age of $28 \mathrm{~d}$ can reach to 83.3\%/1.5 MPa, which is higher than that of NZ filled RPC. This is because of two reasons. One is that there are a lot of interfaces between binder and aggregate for RPC unlike cement paste. The other is that the split tensile test in Ref. 12 was carried out in accordance to the ASTM C 496-90 standard, which is different with the test method in this paper.

Table 11 lists the relative standard deviation of splitting strengths of RPC with different NZ contents at the curing age of $3 \mathrm{~d}$ and $28 \mathrm{~d}$. It can be seen from Table 11 that the discreteness of splitting strength of the composites at curing age of $3 \mathrm{~d}$ and 28 $\mathrm{d}$ are from 0.024 to 0.37 and 0.043 to 0.29 , respectively. It means that the dispersion of NZ in RPC is relatively homogeneous and splitting strength of the composites in each group is relatively stable. 


\subsection{Electrical resistivity}

Fig. 8 shows the electrical resistivity of NZ filled RPC at the curing age of $28 \mathrm{~d}$. It can be seen from Fig.8 that the electrical resistivity of NZ filled RPC decreases with the increase of NZ content. Table 12 gives the decrease rate of electrical resistivity of NZ filled RPC at curing age of $28 \mathrm{~d}$. The maximum decrease rate in electrical resistivity is $20.3 \%$ when the $\mathrm{NZ}$ content is $5.0 \%$.

\subsection{Reinforcing mechanisms}

TG and DTG diagrams of the composites at curing age of $3 \mathrm{~d}$ and $28 \mathrm{~d}$ are shown in Figs. 9 and 10, respectively. The mass loss between $50-300^{\circ} \mathrm{C}$ is due to the dehydration of C-S-H gel, ettringite(Aft) and physically-bonded water[16]. The mass loss step in $400-550^{\circ} \mathrm{C}$ is resulting from the decomposition of $\mathrm{CH}$. In addition, cement hydration degree can be obtained based on the TG results and the calculation method according to Ref. [17]. Furthermore, the water required is $0.23 \mathrm{~g}$ for full hydration per $1 \mathrm{~g}$ cement[18]. The ratio of cement to binder is 0.64 in this paper. Based on the above-mentioned, the cement hydration degree in this paper can be calculated. As shown in Table 13, the hydration degrees of cement at curing age of $3 \mathrm{~d}$ and $28 \mathrm{~d}$ decrease when NZ is added in general. This indicates that NZ has certain inhibitory action to the cement hydration. However, some nano fillers (e.g. carbon nanotubes, nano- $\mathrm{TiO}_{2}$ and nano-SiO${ }_{2}$ ) have strong effect on the cement hydration, especially the hydration in early age [19-22]. The nucleus effect of these nano fillers can not only 
accelerate the cement hydration, but also make the distribution of hydration production more uniform and restricts the size of $\mathrm{CH}$. Therefore, NZ has no nucleus effect to accelerate the hydration process of cement.

Fig. 11 shows the micro-structure of NZ filled RPC. As seen in this figure, many calcium hydroxide $(\mathrm{CH})$ crystals can be observed in the plain RPC. However, $\mathrm{CH}$ is hard to be found in the RPC with NZ. Additionally, when NZ is added into RPC, the composites become denser than the plain RPC. The above phenomenon can be explained as follows. NZ makes the RPC denser, reducing the growth space of $\mathrm{CH}$. As a result, the size of $\mathrm{CH}$ is reduced. In addition, Fig. 12 shows the XRD patterns of $\mathrm{Z} 00$ and Z30 at curing age of $28 \mathrm{~d}$. Crystal face peak intensity of $\mathrm{CH}$ can be obtained and then the $\mathrm{CH}$ orientation can be calculated according to the calculation given in Ref. [23]. The calculation results are listed in Table 14. It can be seen from Table 14 that the $\mathrm{CH}$ orientation degree inside RPC can be reduced as NZ is added into RPC.

Because NZ can't improve the hydration of cement, the compressive and splitting strengths of NZ filled RPC at curing age of $3 \mathrm{~d}$ have no significant improvement. However, NZ can reduce the size and orientation of $\mathrm{CH}$ to modify microstructures. This leads to the distinct enhancement in strengths of RPC with NZ at curing age of $28 \mathrm{~d}$..

Fig. 13 illustrates the distribution of NZ inside RPC. The bright spot in Fig.13 presents $\mathrm{Zr}$ element. It can be seen from Fig.13 that $3.0 \%$ of $\mathrm{NZ}$ can be uniformly dispersed in RPC. However, as shown in Figs. 13 and 14, the agglomeration of NZ inside the composites becomes obvious when the content of NZ reaches to $5.0 \%$. 
Therefore, the addition of $3.0 \%$ of $\mathrm{NZ}$ features the best enhancing effect to mechanical properties of RPC among different NZ content levels. The NZ agglomeration caused by poor NZ dispersion likes the defects inside RPC, thus weakening the reinforcing effect of NZ to RPC. It should be noted from Fig.13 a) that NZ has an extensive distribution inside the composites, which leads to forming of reinforcing network.

The factors affecting the electrical conductivity of NZ filled RPC mainly include content of $\mathrm{NZ}$ and compactness of the composites. On one hand, the addition of $\mathrm{NZ}$ can improve the conductivity of RPC. On the other hand, the presence of NZ can increase the compactness of the composites, which leads to increase in the electrical resistivity. The electrical conductivity of NZ filled RPC is co-affected by double effect of NZ. The results in Fig.8 and Table 12 suggested that the former governs the electrical conductivity of the composites.

\section{Conclusion}

NZ was employed as filler to modify RPC in this research. The effect of different contents of NZ to mechanical and electrical properties of RPC were investigated. In general, the mechanical properties of NZ filled RPC are superior to that of plain RPC. The addition of NZ can improve the conductivity of RPC.

The maximum increases in flexural strength of the composites at curing age of 3 $\mathrm{d}$ and $28 \mathrm{~d}$ were $32.0 \% / 2.46 \mathrm{MPa}$ and $36.6 \% / 4.19 \mathrm{MPa}$, respectively. The increases in compressive strength of the composites at curing age of $3 \mathrm{~d}$ and $28 \mathrm{~d}$ can reach to $6.1 \% / 4.05 \mathrm{MPa}$ and $16.3 \% / 16.18 \mathrm{MPa}$. The splitting strengths at curing age of $3 \mathrm{~d}$ 
decreased when NZ was added, but that at curing age of $28 \mathrm{~d}$ were higher than that of plain RPC when NZ content levels are $3.0 \%$ and $5.0 \%$. The maximum increase in splitting strength of the composites at curing age of $28 \mathrm{~d}$ achieved 34.0\%/1.08 MPa. Although NZ did not accelerate the hydration process of RPC, the microstructure of NZ filled RPC was denser than that of plain RPC. Denser composites can reduce the growth space of $\mathrm{CH}$ crystals, thus reduce the size of $\mathrm{CH}$ crystals. Additionally, NZ can reduce $\mathrm{CH}$ crystal orientation to improve the microstructures of the composites.

$3.0 \% \mathrm{NZ}$ contribution to the mechanical properties of the composites at curing age of $28 \mathrm{~d}$ was the largest among different NZ content levels. High NZ content is beneficial for forming extensive distribution of NZ in the composites. However, the agglomeration of NZ caused by poor NZ dispersion at high content level can weaken the reinforcing effect of NZ to RPC.

NZ can obviously enhance the mechanical and electrical properties and microstructure of RPC. Therefore, it is an effective filler to modify the compressive, flexural and tensile properties of PRC, thus developing cementitious composites with high strength, toughness and durability.

\section{Acknowledgments}

The authors thank the funding supported from the National Science Foundation of China (51578110 and 51428801).

\section{References}

[1] Farzadnia, N., Ali, A., Abdullah, A., and Demirboga, R. (2011). "Incorporation of 
mineral admixtures in sustainable high performance concrete." Int J Sus Constr, 2(1), 1-13.

[2] Ganesh, P., Murthy, A. R. C., Kumar, S. S., Iyer, N. R., and Raj, A. (2014)"An experimental study on evaluation of mechanical properties for nano concrete." Innovations and Advances in Civil Engineering Towards Green and Sustainable System, Coimbatore Institute of Technology, Coimbatore, INDIA.

[3] Richard, P., and Cheyrezy, M. (1995). "Composition of reactive powder concretes." Cem Concr Res, 25(7), 1501-1511.

[4] Reda, M. M., Shrive, N. G., and Gillott, J. E. (1999). "Microstructural investigation of innovative UHPC." Cem Concr Res, 29(3), 323-329.

[5] Richard, P., and Cheyrezy, M. (1995). "Composition of reactive powder concretes." Cem Concr Res, 25(7), 1501-1511.

[6] Bonneau, O., Poulin, C., Dugat, J., Richard, P., and Aitcin, P. C. (1996). "Reactive powder concretes: from theory to practice." Concr Int, 18(4),47-49.

[7] Rashad, A. M. (2014). "A comprehensive overview about the effect of nano- $\mathrm{SiO}_{2}$ on some properties of traditional cementitious materials and alkali-activated fly ash." Constr Build Mater, 52, 437-464.

[8] Kawashima, S., Hou, P., Corr, D. J., and Shah, S. P. (2013). "Modification of cement-based materials with nanoparticles." Cem Concr Compos, 36, 8-15.

[9] Zhang, L., Ma, N., Wang, Y., Han, B., Cui, X., Yu, X., and Ou, J. (2016). "Study on the reinforcing mechanisms of nano silica to cement-based materials with theoretical calculation and experimental evidence." J Compos Mater, DOI: 
$10.1177 / 0021998316632602$.

[10]C Gogtas, HF Lopez, K Sobolev (2016) "Effect of nano-YSZ and nano-ZrO2 additions on the strength and toughness behavior of self-flowing alumina castables" Ceram Int, 2(1), 1847-1855.

[11] Soleymani, F. (2012). "The effects of $\mathrm{ZrO}_{2}$ nanopowders on compressive damage and pore structure properties of concrete specimens." J Am Sci, 8(3), 738-744.

[12]Nazari, A., Riahi, S., Riahi, S., Shamekhi, S. F., and Khademno, A. (2010). "Embedded $\mathrm{ZrO}_{2}$ nanoparticles mechanical properties monitoring in cementitious composites." J Am Sci, 6(4), 86-89.

[13]Nazari, A., Riahi, S., Riahi, S., Shamekhi, S. F., and Khademno, A. (2010). "An investigation on the Strength and workability of cement based concrete performance by using $\mathrm{ZrO}_{2}$ nanoparticles." J Am Sci, 6(4), 29-33.

[14]Nazari, A., and Riahi, S. (2011). "Limewater effects on properties of $\mathrm{ZrO}_{2}$ nanoparticle blended cementitious composite." J Compos Mater, 45(6), 639-644.

[15]Han, B.G. , Guan, X.C. , Ou, J.P. (2007). "Electrode design, measuring method and data acquisition system of carbon fiber cement paste piezoresistive sensors." Sen. and Act. A, 135(2), 360-369.

[16]Peschard, A., Govin, A., Grosseau, P., Guilhot, B., and Guyonnet, R. (2004). "Effect of polysaccharides on the hydration of cement paste at early ages." Cem Concr Res, 34(11), 2153-2158.

[17]Yu, R., Spiesz, P., and Brouwers, H. (2014). "Effect of nano-silica on the hydration and microstructure development of Ultra-High Performance Concrete 
(UHPC) with a low binder amount." Constr Build Mater, 65(9), 140-150.

[18]Madani, H., Bagheri, A., and Parhizkar, T. (2012). "The pozzolanic reactivity of monodispersed nanosilica hydrosols and their influence on the hydration characteristics of Portland cement." Cem Concr Res, 42(12), 1563-1570.

[19]Han, B., Dong, S., Ou, J., Zhang, C., Wang, Y., Yu, X., and Ding, S. (2016). "Microstructure related mechanical behaviors of short-cut super-fine stainless wire reinforced reactive powder concrete." Mater Des, 96, 16-26.

[20]Han, B., Sun, S., Ding, S., Zhang, L., Yu, X., and Ou, J. (2015). "Review of nanocarbon-engineered multifunctional cementitious composites." Compos Part A, 70(70), 69-81.

[21]Nazari, A., and Riahi, S. (2011). " $\mathrm{TiO}_{2}$ nanoparticles' effects on properties of concrete using ground granulated blast furnace slag as binder." Sci China Technol Sci, 54(11), 3109-3118.

[22]Zhang, L., Ding, S., Sun, S., Han, B., and Yu, X. (2016). Chapter 2: Nano-scale behavior and nano-modification of cement and concrete materials. Advanced Research on Nanotechnology for Civil Engineering Applications, Anwar Khitab, Waqas Anwar, IGI Global, USA, 28-79.

[23]Qing, Y., Zenan, Z., Deyu, K., and Rongshen, C. (2007). "Influence of nano-SiO ${ }_{2}$ addition on properties of hardened cement paste as compared with silica fume." Constr Build Mater, 21(3), 539-545. 


\section{Figures}

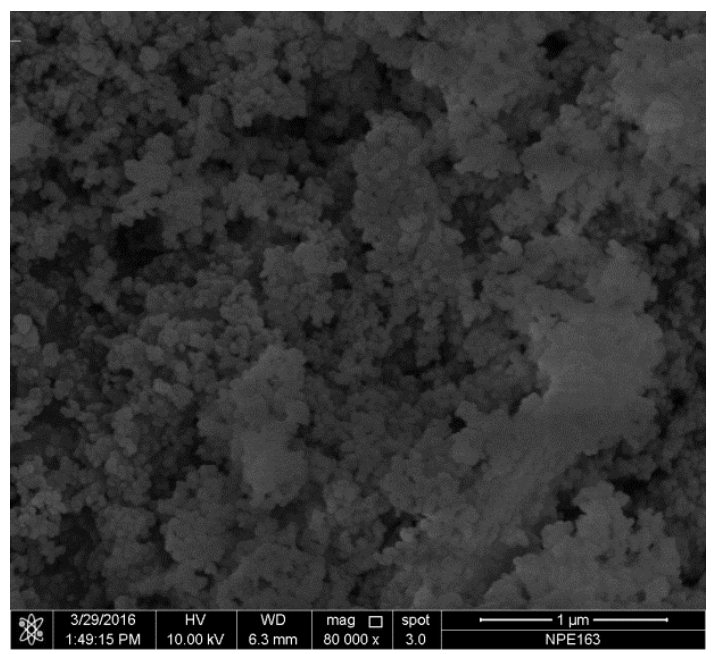

Fig. 1 SEM image of NZ

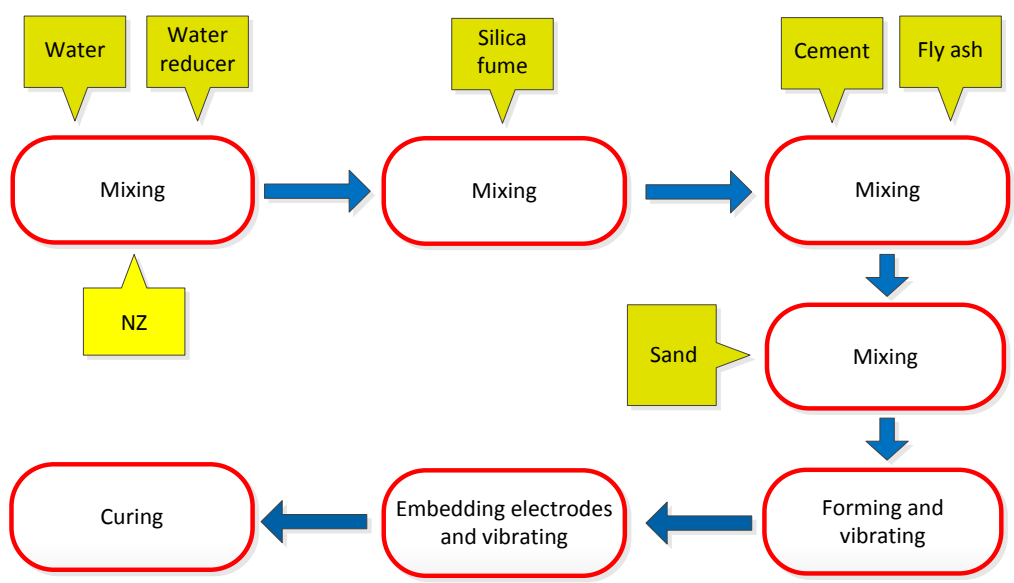

Fig. 2 Preparation process of the composites
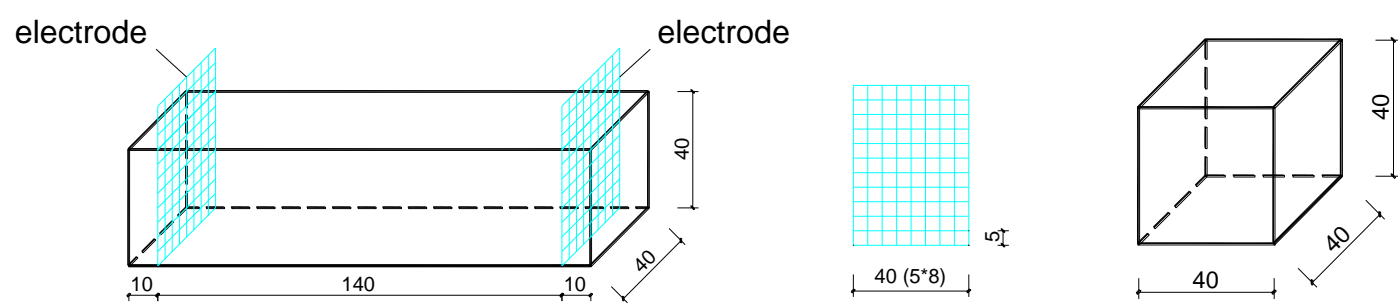

(a)

(b)

Fig. 3 Dimension of the specimens and electrode arrangement 


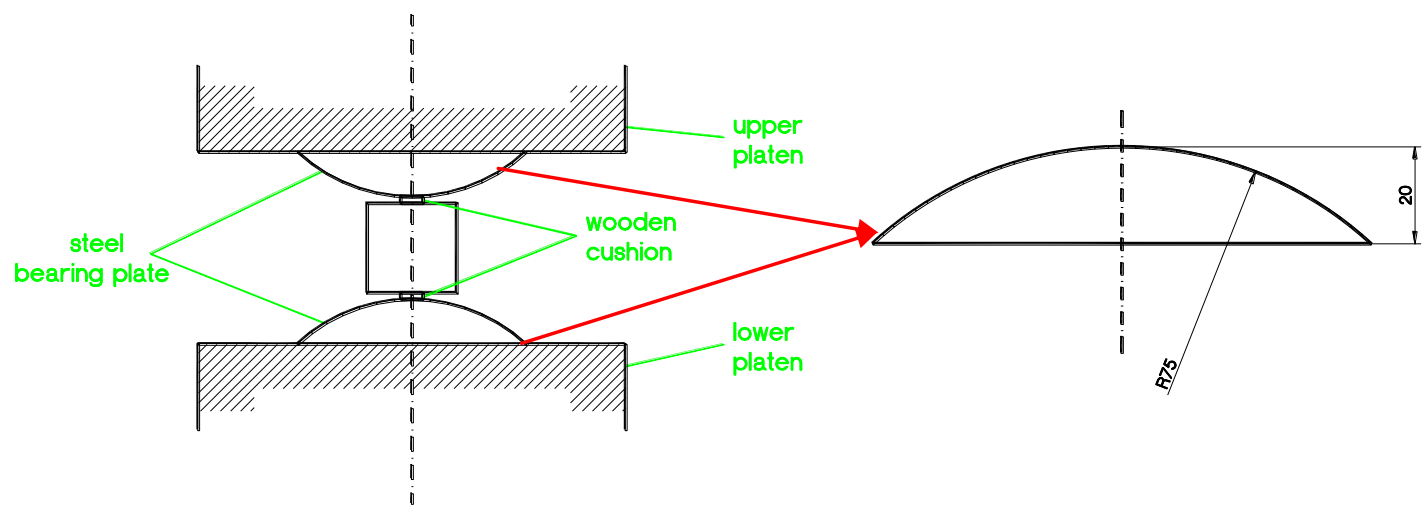

Fig. 4 Loading process of specimen under splitting tension

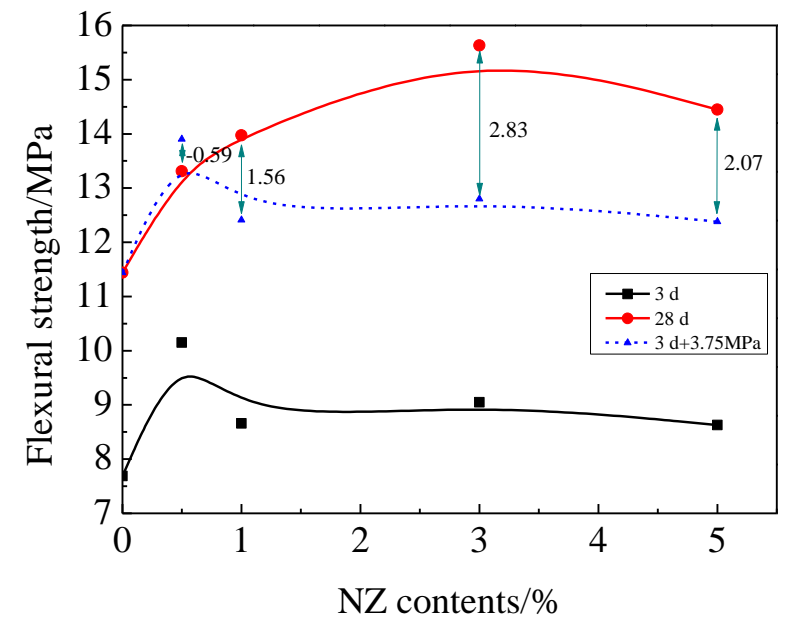

Fig. 5 Flexural strength of the composites at curing age of $3 \mathrm{~d}$ and $28 \mathrm{~d}$

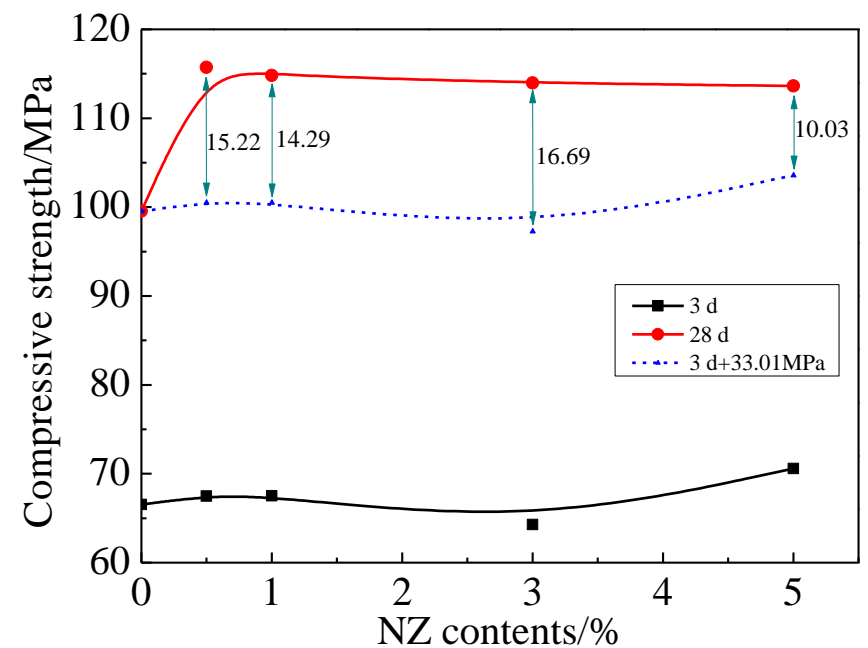

Fig. 6 Compressive strength of the composites at curing age of $3 \mathrm{~d}$ and $28 \mathrm{~d}$ 


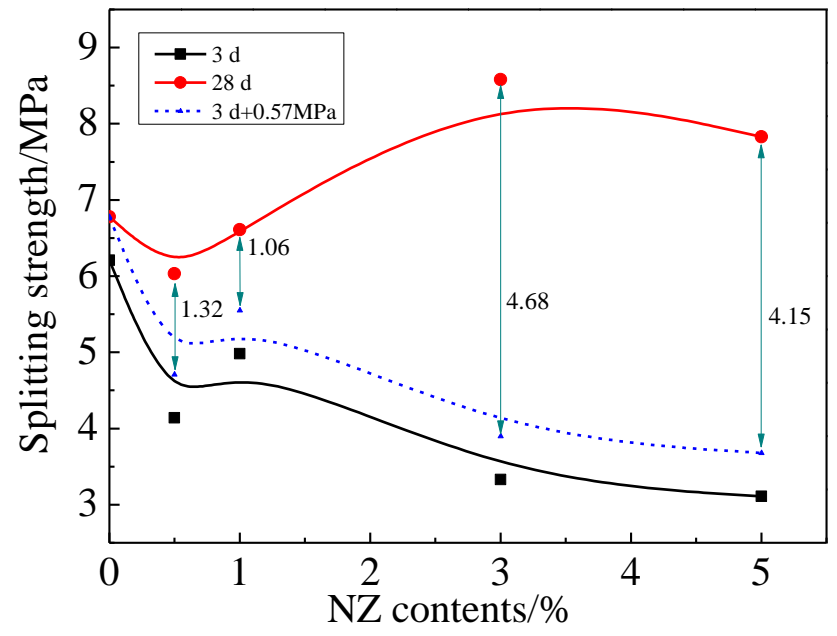

Fig. 7 Splitting strength of the composites at curing age of $3 \mathrm{~d}$ and $28 \mathrm{~d}$

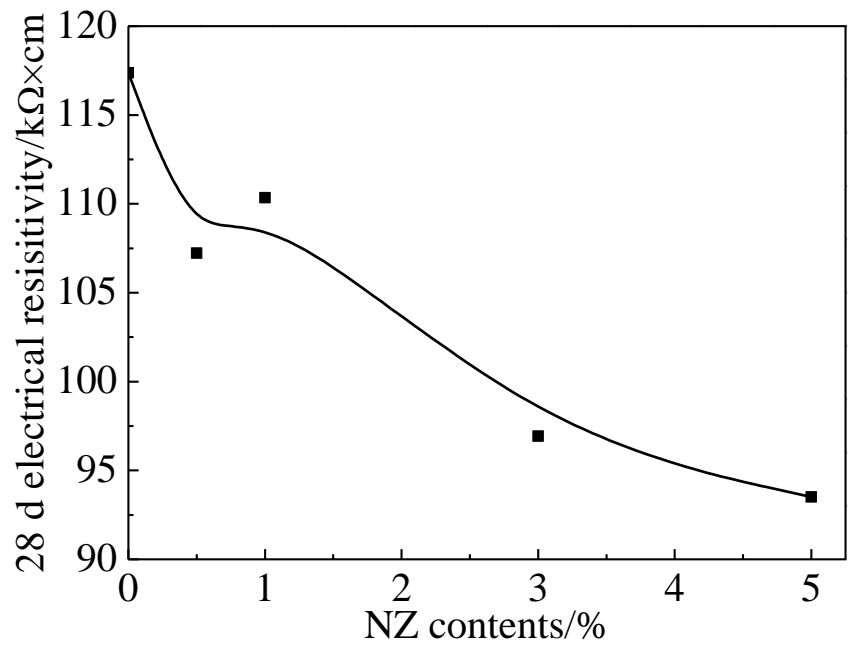

Fig. 8 Electrical resistivity of the composites at the curing age of $28 \mathrm{~d}$

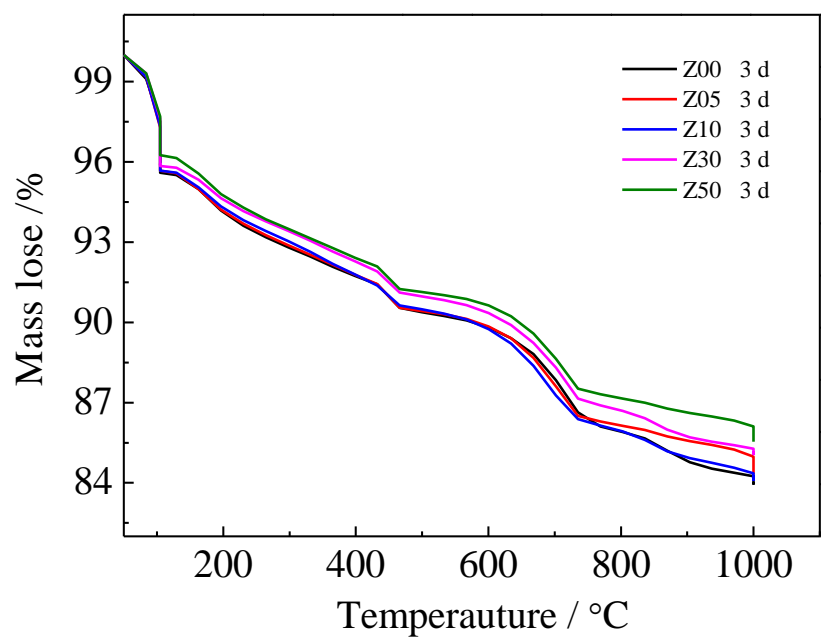


(a) TG diagram

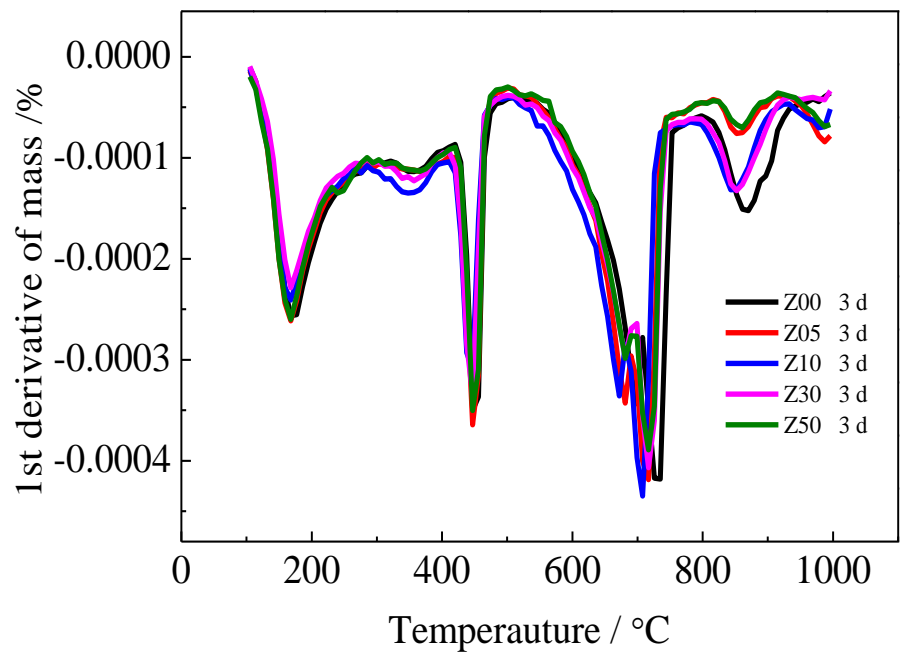

(b) DTG diagram

Fig. 9 TG diagram (a) and DTG diagram (b) for Z00(without NZ), Z05(with 0.5\% of NZ), Z10(with $1.0 \%$ of NZ), Z30(with $3.0 \%$ of NZ) and Z50(with5.0\% of NZ) at curing age of $3 \mathrm{~d}$

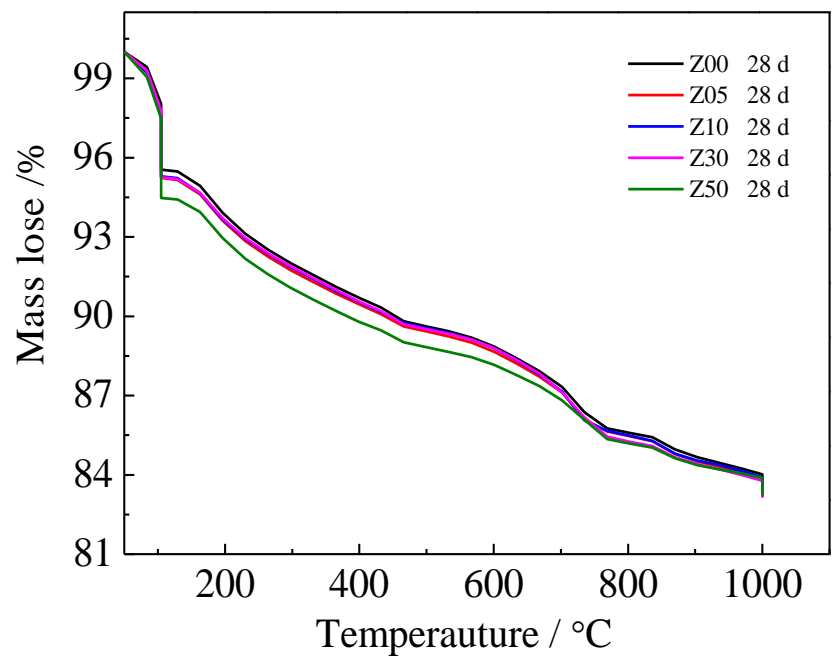

(a) TG diagram

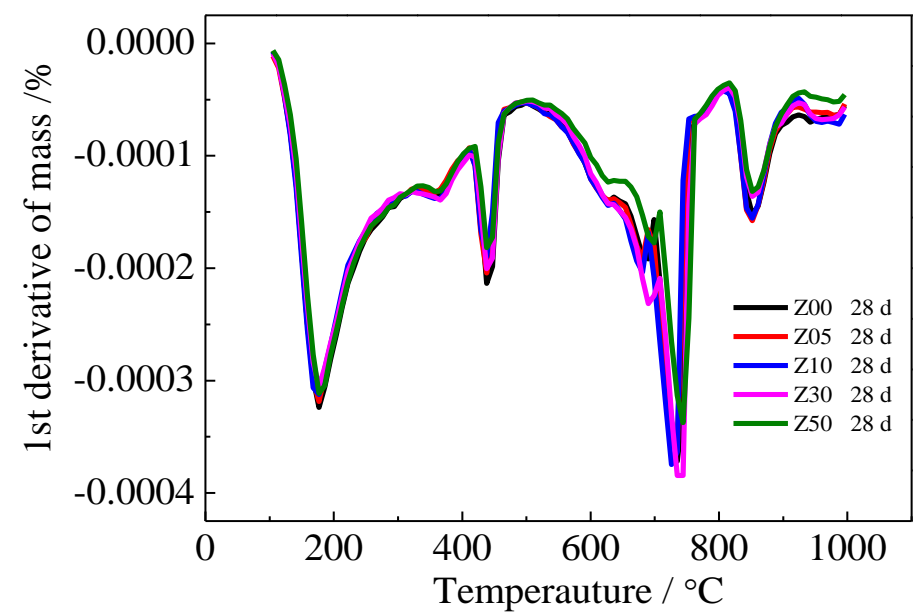


(b) DTG diagram

Fig. 10 TG diagram (a) and DTG diagram (b) for Z00(without NZ), Z05(with $0.5 \%$ of NZ), Z10(with $1.0 \%$ of NZ), Z30(with $3.0 \%$ of NZ) and Z50(with5.0\% of NZ) at curing age of $28 \mathrm{~d}$

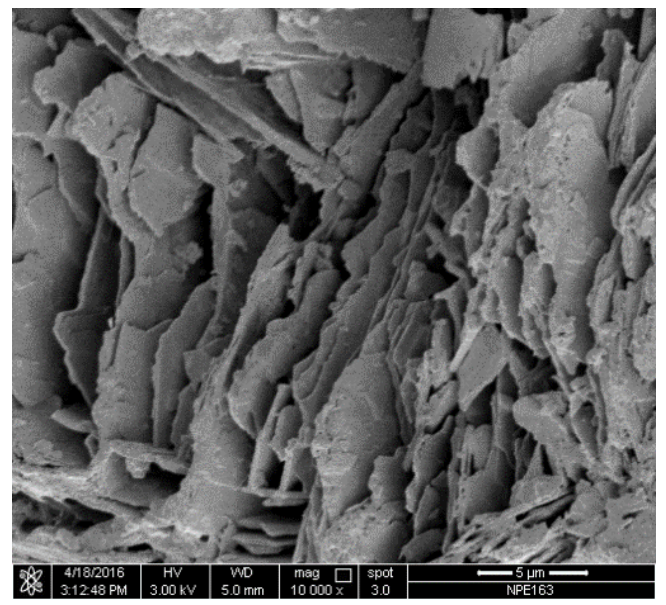

Z00 (without NZ)

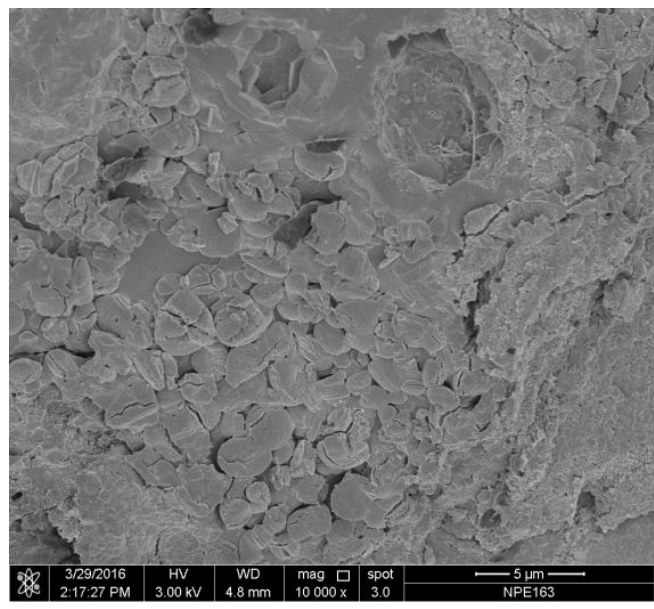

Z10(with $1.0 \%$ of NZ)

Fig. 11 SEM images of RPC without and with NZ

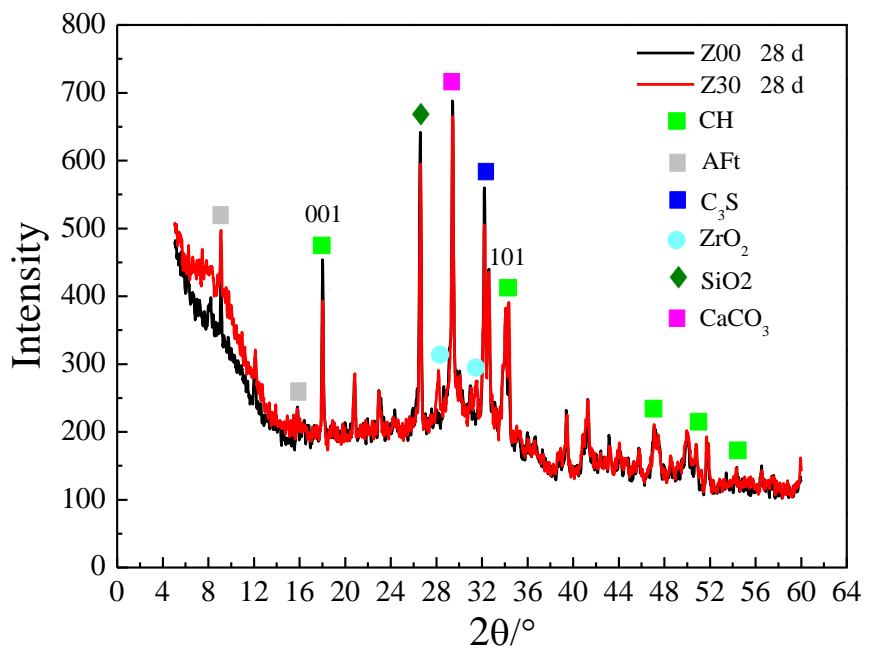

Fig. 12 XRD patterns of Z00 (without NZ) and Z30(with 3.0\% of NZ) at $28 \mathrm{~d}$

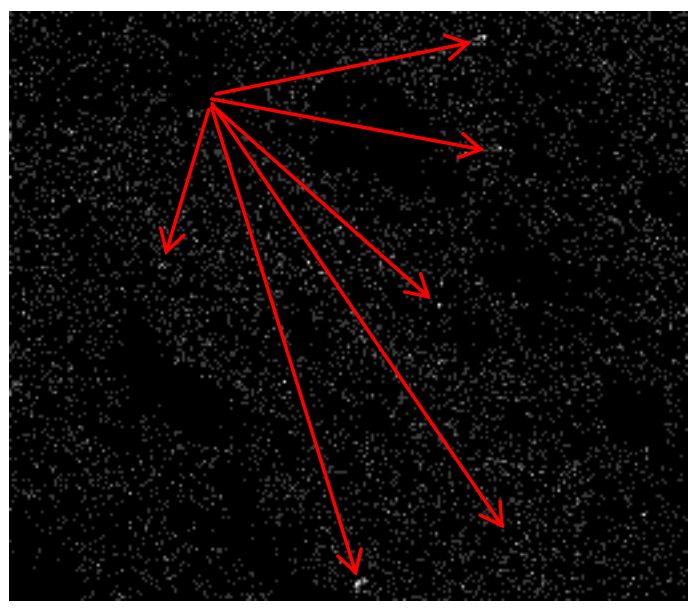

(a) Z30 (with $3.0 \% \mathrm{NZ}$ )

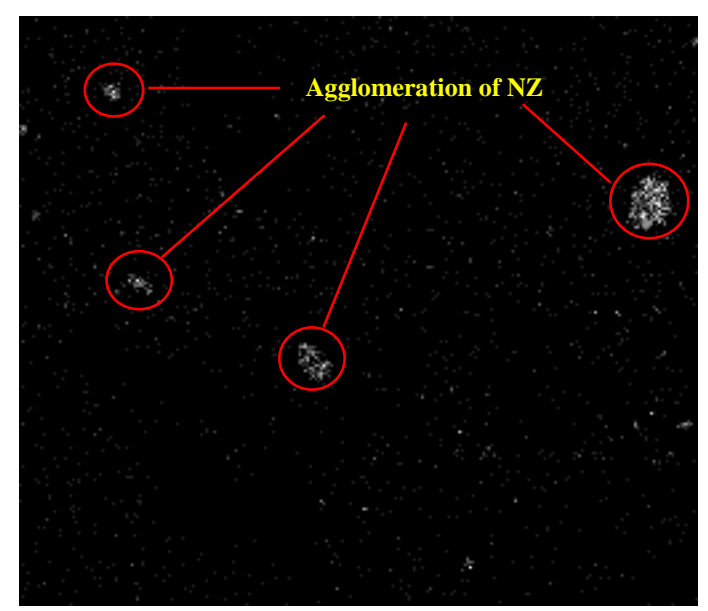

(b) Z50 (with 5.0\% NZ) 
Fig. 13 ESEM images of NZ filled RPC (200×)

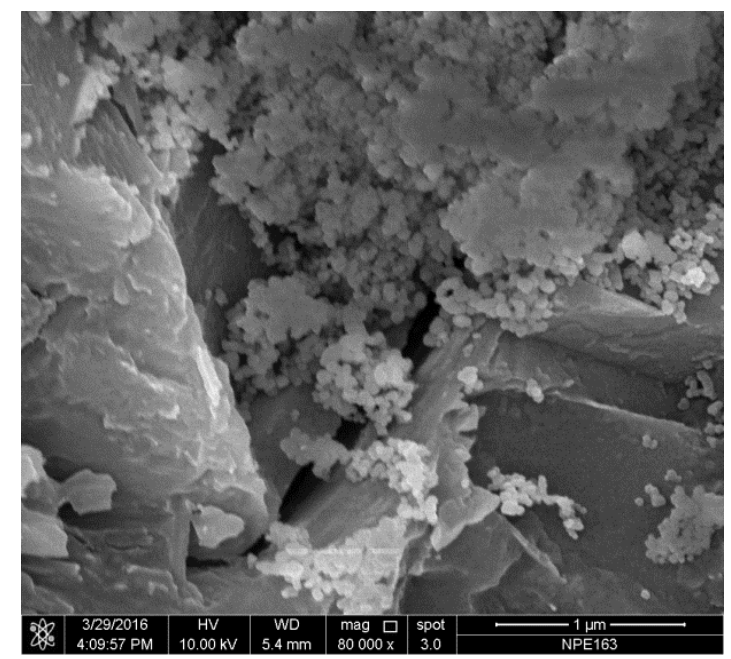

Fig. 14 The aggregation of NZ inside Z50(with 5.0\% NZ) 
Tables

Table 1. Mix proportions of NZ filled RPC

\begin{tabular}{cccccccc}
\hline $\begin{array}{c}\text { Sample } \\
\text { codes }\end{array}$ & Cement & Fly ash & $\begin{array}{c}\text { Silica } \\
\text { fume }\end{array}$ & Sand & Water & $\begin{array}{c}\text { Water } \\
\text { reducer }\end{array}$ & NZ \\
\hline Z00 & 0.8 & 0.2 & 0.25 & 1.1 & 0.3 & $0.5 \%$ & 0 \\
Z05 & 0.796 & 0.2 & 0.25 & 1.1 & 0.3 & $0.54 \%$ & $0.5 \%$ \\
Z10 & 0.792 & 0.2 & 0.25 & 1.1 & 0.3 & $0.54 \%$ & $1.0 \%$ \\
Z30 & 0.776 & 0.2 & 0.25 & 1.1 & 0.3 & $0.69 \%$ & $3.0 \%$ \\
Z50 & 0.76 & 0.2 & 0.25 & 1.1 & 0.3 & $0.83 \%$ & $5.0 \%$ \\
\hline
\end{tabular}

Table 2. Mix proportions of NZ filled cement pastes for TG and XRD test

\begin{tabular}{ccccccc}
\hline Sample codes & Cement & Fly ash & Silica fume & Water & Water reducer & NZ \\
\hline Z00 & 0.8 & 0.2 & 0.25 & 0.3 & $0.5 \%$ & 0 \\
Z05 & 0.796 & 0.2 & 0.25 & 0.3 & $0.54 \%$ & $0.5 \%$ \\
Z10 & 0.792 & 0.2 & 0.25 & 0.3 & $0.54 \%$ & $1.0 \%$ \\
Z30 & 0.776 & 0.2 & 0.25 & 0.3 & $0.69 \%$ & $3.0 \%$ \\
Z50 & 0.76 & 0.2 & 0.25 & 0.3 & $0.83 \%$ & $5.0 \%$ \\
\hline
\end{tabular}

Table 3. The relative increase rate in flexural strengths of RPC with different NZ contents at curing age of $3 \mathrm{~d}$ and $28 \mathrm{~d} / \%$

\begin{tabular}{cccccc}
\hline Age & Z00 & Z05 & Sample codes & Z10 & Z30 \\
\hline $3 \mathrm{~d}$ & 0 & 32.0 & 12.6 & 17.6 & 12.2 \\
$28 \mathrm{~d}$ & 0 & 16.4 & 22.1 & 36.6 & 26.3 \\
\hline
\end{tabular}

Table 4. The absolute increase in flexural strengths of RPC with different NZ contents at curing age of $3 \mathrm{~d}$ and $28 \mathrm{~d} / \mathrm{MPa}$

\begin{tabular}{|c|c|c|c|c|c|}
\hline \multirow{2}{*}{ Age } & \multicolumn{5}{|c|}{ Sample codes } \\
\hline & $\mathrm{Z} 00$ & $\mathrm{Z} 05$ & $\mathrm{Z} 10$ & Z30 & $\mathrm{Z} 50$ \\
\hline $3 \mathrm{~d}$ & 0 & 2.46 & 0.97 & 1.36 & 0.94 \\
\hline $28 \mathrm{~d}$ & 0 & 1.87 & 2.53 & 4.19 & 3.01 \\
\hline
\end{tabular}

Table 5. The relative standard deviation of flexural strengths of RPC with different NZ contents at curing age of $3 \mathrm{~d}$ and $28 \mathrm{~d} / \%$

\begin{tabular}{|c|c|c|c|c|c|}
\hline \multirow{2}{*}{ Age } & \multicolumn{5}{|c|}{ Sample codes } \\
\hline & $\mathrm{Z} 00$ & $\mathrm{Z} 05$ & $\mathrm{Z} 10$ & $\mathrm{Z} 30$ & $\mathrm{Z} 50$ \\
\hline
\end{tabular}




\begin{tabular}{cccccc}
\hline $3 \mathrm{~d}$ & 9.5 & 3.0 & 4.1 & 0.7 & 5.2 \\
$28 \mathrm{~d}$ & 5.2 & 6.1 & 7.6 & 6.7 & 1.9 \\
\hline
\end{tabular}

Table 6. The relative increase rate of compressive strengths of RPC with different NZ contents at curing age of $3 \mathrm{~d}$ and $28 \mathrm{~d} / \%$

\begin{tabular}{cccccc}
\hline Age & Z00 & Z05 & Sample codes & Z10 & Z30 \\
\hline $3 \mathrm{~d}$ & 0 & 1.4 & 1.5 & -3.4 & 6.1 \\
$28 \mathrm{~d}$ & 0 & 16.3 & 15.3 & 14.5 & 14.1 \\
\hline
\end{tabular}

Table 7. The absolute increase of compressive strengths of RPC with different

$\mathrm{NZ}$ contents at curing age of $3 \mathrm{~d}$ and $28 \mathrm{~d} / \mathrm{MPa}$

\begin{tabular}{|c|c|c|c|c|c|}
\hline \multirow{2}{*}{ Age } & \multicolumn{5}{|c|}{ Sample codes } \\
\hline & $\mathrm{Z} 00$ & $\mathrm{Z} 05$ & $\mathrm{Z} 10$ & $\mathrm{Z} 30$ & $\mathrm{Z} 50$ \\
\hline $3 d$ & 0 & 0.96 & 0.98 & -2.27 & 4.05 \\
\hline $28 \mathrm{~d}$ & 0 & 16.18 & 15.27 & 14.42 & 14.08 \\
\hline
\end{tabular}

Table 8. The relative standard deviation of compressive strengths of RPCs with different NZ contents at curing age of $3 \mathrm{~d}$ and $28 \mathrm{~d} / \%$

\begin{tabular}{|c|c|c|c|c|c|}
\hline \multirow{2}{*}{ Age } & \multicolumn{5}{|c|}{ Sample codes } \\
\hline & $\mathrm{Z} 00$ & $\mathrm{Z} 05$ & $\mathrm{Z} 10$ & $\mathrm{Z} 30$ & $\mathrm{Z} 50$ \\
\hline $3 \mathrm{~d}$ & 3.2 & 8.6 & 4.8 & 3.0 & 5.2 \\
\hline $28 \mathrm{~d}$ & 4.9 & 7.4 & 4.0 & 2.8 & 4.3 \\
\hline
\end{tabular}

Table 9. The relative increase rate in splitting strengths of RPC with different

$\mathrm{NZ}$ contents at curing age of $3 \mathrm{~d}$ and $28 \mathrm{~d} / \%$

\begin{tabular}{|c|c|c|c|c|c|}
\hline \multirow{2}{*}{ Age } & \multicolumn{5}{|c|}{ Sample codes } \\
\hline & $\mathrm{Z} 00$ & Z05 & $\mathrm{Z} 10$ & $\mathrm{Z} 30$ & $\mathrm{Z} 50$ \\
\hline $3 \mathrm{~d}$ & 0 & -33.3 & -19.8 & -46.4 & -49.9 \\
\hline $28 \mathrm{~d}$ & 0 & -5.8 & -3.3 & 34.0 & 22.3 \\
\hline
\end{tabular}


Table 10. The absolute increase in splitting strengths of RPC with different NZ contents at curing age of $3 \mathrm{~d}$ and $28 \mathrm{~d} / \mathrm{MPa}$

\begin{tabular}{|c|c|c|c|c|c|}
\hline \multirow{2}{*}{ Age } & \multicolumn{5}{|c|}{ Sample codes } \\
\hline & $\mathrm{Z} 00$ & Z05 & $\mathrm{Z} 10$ & $\mathrm{Z} 30$ & Z50 \\
\hline $3 \mathrm{~d}$ & 0 & -2.07 & -1.23 & -2.88 & -3.10 \\
\hline $28 \mathrm{~d}$ & 0 & -0.75 & -0.17 & 1.08 & 1.05 \\
\hline
\end{tabular}

Table 11. The relative standard deviation of splitting strengths of RPC with different NZ contents at curing age of $3 \mathrm{~d}$ and $28 \mathrm{~d} / \%$

\begin{tabular}{|c|c|c|c|c|c|}
\hline \multirow{2}{*}{ Age } & \multicolumn{5}{|c|}{ Sample codes } \\
\hline & $\mathrm{Z} 00$ & $\mathrm{Z} 05$ & $\mathrm{Z} 10$ & $\mathrm{Z} 30$ & $\mathrm{Z} 50$ \\
\hline $3 d$ & 7.2 & 2.4 & 37.1 & 3.3 & 5.6 \\
\hline $28 \mathrm{~d}$ & 5.2 & 8.9 & 7.7 & 4.3 & 29.0 \\
\hline
\end{tabular}

Table 12. The decrease rate in electrical resistivity of the composites at the curing age of $28 \mathrm{~d} / \%$

\begin{tabular}{cccccc}
\hline \multirow{2}{*}{ Age } & Z00 & Z05 & Sample codes \\
& 0 & 8.6 & 6.0 & 10 & Z30 \\
\hline $28 \mathrm{~d}$ & 0 & 850 & 20.3 \\
\hline
\end{tabular}

Table 13. Cement hydration degree at curing age of $3 \mathrm{~d}$ and $28 \mathrm{~d} / \%$

\begin{tabular}{cccccc}
\hline Age & \multicolumn{5}{c}{ Sample codes } \\
\hline $3 \mathrm{~d}$ & 55.7 & 52.5 & 53.3 & 49.4 & 50.0 \\
$28 \mathrm{~d}$ & 64.7 & 63.4 & 63.0 & 61.7 & 59.7 \\
\hline
\end{tabular}

Table 14. Diffraction intensity and orientation of $\mathrm{CH}$ at curing age of $28 \mathrm{~d}$

\begin{tabular}{cccc}
\hline Sample codes & $(001) \mathrm{CH}$ & $(101) \mathrm{CH}$ & $\mathrm{CH}$ orientation \\
\hline Z00 & 453 & 361 & 1.69 \\
Z30 & 393 & 391 & 1.36 \\
\hline
\end{tabular}

